\title{
Ventilatory Limitation of Exercise in Pediatric Subjects Evaluated for Exertional Dyspnea
}

\author{
Paolo T. Pianosi ${ }^{1 * t}$ and Joshua R. Smith ${ }^{2}$ \\ ${ }^{1}$ Department of Pediatric and Adolescent Medicine, Mayo Clinic, Rochester, MN, United States, ${ }^{2}$ Department \\ of Cardiovascular Medicine, Mayo Clinic, Rochester, MN, United States
}

\section{OPEN ACCESS}

Edited by:

Luca Paolo Ardigò,

University of Verona, Italy

Reviewed by:

Dharini M. Bhammar,

University of Nevada, Las Vegas,

United States

Erik Hulzebos,

University Medical Center Utrecht,

Netherlands

Jordan A. Guenette,

The University of British Columbia,

Canada

*Correspondence:

Paolo T. Pianosi

ppianosi@umn.edu

${ }^{\dagger}$ Present address:

Paolo T. Pianosi,

Division of Pediatric Pulmonary and Sleep Medicine, Department of Pediatrics, University of Minnesota,

Minneapolis, MN, United States

Specialty section:

This article was submitted to

Exercise Physiology,

a section of the journal

Frontiers in Physiology

Received: 14 October 2018

Accepted: 10 January 2019

Published: 29 January 2019

Citation:

Pianosi PT and Smith JR (2019) Ventilatory Limitation of Exercise in Pediatric Subjects Evaluated

for Exertional Dyspnea.

Front. Physiol. 10:20.

doi: 10.3389/fphys.2019.00020
Purpose: Attribution of ventilatory limitation to exercise when the ratio of ventilation $\left(\dot{V}_{E}\right)$ at peak work to maximum voluntary ventilation (MV) exceeds 0.80 is problematic in pediatrics. Instead, expiratory flow limitation (EFL) measured by tidal flow-volume loop (FVL) analysis - the method of choice - was compared with directly measured MVV or proxies to determine ventilatory limitation.

Methods: Subjects undergoing clinical evaluation for exertional dyspnea performed maximal exercise testing with measurement of tidal FVL. EFL was defined when exercise tidal FVL overlapped at least $5 \%$ of the maximal expiratory flow-volume envelope for $>5$ breaths in any stage of exercise. We compared this method of ventilatory limitation to traditional methods based on MV or multiples $(30,35$, or 40 ) of FEV 1 . Receiver operating characteristic curves were constructed and area under curve (AUC) computed for peak $\dot{V}_{E} / \mathrm{MVV}$ and peak $\dot{V}_{E} / x \cdot \mathrm{FEV}_{1}$.

Results: Among 148 subjects aged $7-18$ years (60\% female), EFL was found in 87 (59\%). Using EFL shown by FVL analysis as a true positive to determine ventilatory limitation, AUC for peak $\dot{V}_{E} / 30 \cdot \mathrm{FEV}_{1}$ was 0.84 (95\% Cl 0.78-0.90), significantly better than AUC 0.70 (95\% Cl 0.61-0.79) when 12-s sprint MVV was used for peak $\dot{V}_{E} / \mathrm{MVV}$. Sensitivity and specificity were 0.82 and 0.70 respectively when using a cutoff of 0.85 for peak $\dot{V}_{E} / 30 \cdot \mathrm{FEV}_{1}$ to predict ventilatory limitation to exercise.

Conclusion: Peak $\dot{V}_{E} / 30 \cdot \mathrm{FEV}_{1}$ is superior to peak $\dot{V}_{E} / \mathrm{MVV}$, as a means to identify potential ventilatory limitation in pediatric subjects when FVL analysis is not available.

Keywords: flow-volume curve, flow limitation, ventilation, dyspnea, exercise, children

\section{INTRODUCTION}

The ventilatory response to exercise changes through childhood and adolescence (Cooper et al., 1987). Younger children have higher ventilatory equivalents (Armstrong et al., 1997; Prioux et al., $1997)$ such that they achieve levels of ventilation $\left(\dot{V}_{E}\right)$ near maximum voluntary ventilation (MVV) at peak work (Godfrey, 1974); but this morphs through adolescence until peak $\dot{V}_{E} / \mathrm{MVV}$ ratio reaches typical adult levels (Rowland and Cunningham, 1997; Giardini et al., 2011). Pre-pubertal children develop significant expiratory flow limitation (EFL) during exercise (Nourry et al., 2006; 
Swain et al., 2010; Borel et al., 2014) with the prevalence of EFL decreasing post-puberty due at least in part to lower ventilatory requirement (Emerson et al., 2015; Smith et al., 2015). It behooves one to understand EFL during exercise as it may limit $\dot{V}_{E}$, worsen dyspnea, or reduce capacity (Dempsey et al., 2008; Babb, 2013).

Cardiopulmonary exercise testing is used clinically to investigate exertional dyspnea. The traditional method of assessing ventilatory limitation is based on breathing reserve (Ross, 2003):

$$
100 \% \cdot\left[1-\operatorname{peak} \dot{V}_{E} / \mathrm{MVV}\right]
$$

This approach is problematic as it ignores the fact that the maximal voluntary ventilation (MVV) maneuver does not mimic the breathing pattern or respiratory mechanics that occur during exercise (Klas and Dempsey, 1989; Agostoni et al., 2011). Prevailing wisdom in pediatric exercise medicine maintains that children achieve "near to or slightly less than $70 \%$ of their MVV at maximal ventilation" (Orenstein, 1993; Takken et al., 2017) but this observation has never been directly tested. Furthermore, proxy measures for MVV based on multiples of $\mathrm{FEV}_{1}$ are often used rather than direct measurement of MVV but only $35 \cdot \mathrm{FEV}_{1}$ has been examined in a pediatric population. Specifically, Fulton et al. (1995) found that MVV was similar to the proxy measure of MVV viz 35. $\mathrm{FEV}_{1}$ in healthy African-American, adolescent girls. Furthermore, a recent study found that conclusions from test results depend on which surrogate for MVV is chosen only compounds interpretation challenges (Colwell and Bhatia, 2017). Taken together, it is not at all clear whether directly measured MVV or multiples of $\mathrm{FEV}_{1}$ as proxies for MVV reflect EFL and therefore ventilatory limitation during exercise in children and adolescents.

Thus, the central question of this study is whether a simple, reproducible test that incorporates confounding and inter-related variables such as age, sex, and height, enables one to confidently identify whether a subject would exhibit EFL during exercise. Tidal flow-volume loop (FVL) analysis was used as the method of choice to confirm EFL during exercise and compare with directly measured MVV vs. multiples of $\mathrm{FEV}_{1}$ as proxies for MVV. We hypothesized that a proxy measure of MVV based on $\mathrm{FEV}_{1}$ predicts development of EFL and ventilatory limitation during exercise in pediatric subjects undergoing testing for investigation of exertional dyspnea.

\section{MATERIALS AND METHODS}

\section{Subjects}

Medical records of children and adolescents up to 18 years of age seen at Mayo Clinic from 2007 to 2014, who underwent clinically indicated, maximal exercise tests with FVL analysis as part of clinical evaluation of exertional dyspnea were audited retrospectively. Subjects with exercise-induced laryngeal obstruction that was diagnosed by continuous laryngoscopy during exercise were excluded. The cohort was comprised of patients with known asthma who still complained of exertional dyspnea despite aggressive therapy, patients with disease in other organ systems affecting the respiratory system, and subjects evaluated for exertional dyspnea or chest pain in which no cause was found and thus had no specific medical diagnosis. Diagnosis of asthma required a history of compatible symptoms plus evidence of airway hyperreactivity or bronchodilator responsiveness. Patients with asthma were clinically stable when tested. Informed consent was not required as testing was conducted for clinical indications. Minnesota statute permits retrospective chart review for an IRB approved protocol. Mayo Clinic Institutional Review Board approved the study with waiver of consent.

\section{Pulmonary Function Tests}

Routine instructions for pulmonary function testing (PFTs) included avoiding short-acting bronchodilator for at least $4 \mathrm{~h}$ and long-acting bronchodilators for at least $12 \mathrm{~h}$. All subjects performed PFTs immediately prior to exercise on the same MedGraphics system used for the exercise test (see below) according to ATS/ERS criteria (Miller et al., 2005). Subjects performed PFTs while seated on the cycle ergometer and their largest maximum expiratory flow-volume envelope was used for analysis. PFTs were expressed as percent of predicted (Knudson et al., 1983). MVV was measured in all subjects by the 12-s sprint method on a Jaeger MasterScreen, on the same day as exercise or within the same week (median [IQR] time 0 [0-4] days) in a subset of subjects undergoing bronchoprovocation challenge (to complete workup for exertional dyspnea). Post exercise PFTs were performed only at the discretion of the triage physician, as all testing was done for clinical indications.

\section{Exercise Test}

Subjects were instructed to fast $2 \mathrm{~h}$ before the test. They performed a maximal exercise test on a Corival V3 cycle ergometer. We employed James' protocol consisting of three programs for three ranges of body surface area starting at $200 \mathrm{~kg} \mathrm{~m} \mathrm{~min}{ }^{-1}$ with increments of 100 or $200 \mathrm{~kg} \mathrm{~m} \mathrm{~min}^{-1}$ every $3 \mathrm{~min}$ depending on body surface area prior to 2008 (James, 1981). All subsequent tests were done using Godfrey protocol (Godfrey, 1974) starting at 10 to $25 \mathrm{~W}$, with step increments of 10 to $25 \mathrm{~W} \mathrm{~min}{ }^{-1}$ based on subject's height and sex, in order to obtain test duration of $10 \pm 2 \mathrm{~min}$. Patients were strongly encouraged to exercise to volitional fatigue in order to achieve criteria (e.g., gas exchange ratio $>1.1$, $\mathrm{HR}>190 \mathrm{bpm}$ ) implying maximal effort. Heart rate and $\mathrm{SpO}_{2}$ were monitored continuously with a 12-lead ECG and pulse oximetry, respectively. Blood pressure was measured every other workload.

\section{Ventilatory Measurements During Exercise}

Ventilation and gas exchange were measured breath-by-breath via MedGraphics CPX/D (Breeze software) that employs a Pitot tube to measure flow, electronically integrated to yield volume. The software corrects for drift that occurs when inspiratory and expiratory volumes differed. Exhaled gasses 
were measured by mass spectrometry. System calibration was done prior to every exercise test. The Breeze $($ p program measures EFL according to method described by Johnson et al. (1995) at Mayo Clinic. In short, the degree of EFL was obtained by aligning a tidal breath during exercise within the maximum expiratory flow-volume curve. Alignment was achieved by having subjects perform an inspiratory capacity (IC) maneuver from end-expiratory lung volume. The program permits review of individual FVLs on a breath by breath basis, and automatically computes percent overlap of tidal breath with maximum expiratory FVL. ERV expiratory reserve volume was calculated by subtracting IC from forced vital capacity. IC maneuvers were rehearsed prior to exercise until subjects demonstrated acceptable consistent maneuvers. Once exercise began, an IC maneuver was repeated during a 3-min warm-up at the first workload, then every other load (alternating with blood pressure) until the respiratory compensation point, after which most subjects were able to perform only 1-2 more loads before blood pressure check at peak exercise.

\section{Definition of EFL}

Consensus definition of EFL has not yet been formulated. Nourry et al. (2005) defined EFL to occur when "part of the exercise FVL met the boundary of the expiratory portion of the maximum expiratory FVL determined before exercise" and considered subjects to be flow limited when EFL was observed over $\geq 5 \%$ exercise tidal volume, maintained up to peak work. Swain et al. (2010) similarly defined EFL when intersection of the exercise tidal loop and maximal FVL was $>5 \%$ for any breath. We defined EFL as $\geq 5 \%$ tidal volume overlap with the maximum expiratory flow-volume envelope for $>5$ breaths during sub-maximal or peak exercise.

\section{Statistical Analysis}

Comparisons between subjects with and without EFL were evaluated using two-sample $t$ - or $\chi^{2}$ tests as appropriate. Different multiples $(x)$ of $\mathrm{FEV}_{1}$ were calculated and predictive ability using area under curve (AUC) was computed from ROC curves plotted for peak $\dot{V}_{E} / \mathrm{MVV}$ and peak $\dot{V}_{E} / x \cdot \mathrm{FEV}_{1}$, using presence of EFL as the method of choice to determine exercise limited by ventilation. Optimal cutoff was chosen as the value with highest sensitivity and specificity using the point closest to perfect separation. This analysis was done using $\mathrm{R}$ software v. 3.2.3, with significance set at $p<0.05$. We dichotomized subject into flow limited and non-flow limited, such that EFL was a fixed factor and workload was fitted as a within-subjects factor, to analyze behavior of operating lung volume during exercise between subjects with vs. without EFL. Changes in operating lung volume were calculated as change from rest in expiratory reserve volume (ERV) and IC as fractions of a one's VC; i.e., ERV/VC and IC/VC. As these were not measured at every workload, they were binned according to relative exercise intensity: 8-19, 20-55, and 55-90\% peak workload for analysis. A mixed effects regression model was fit to assess the effect of EFL on ERV/VC and on IC/VC at different workloads using Stata v.14.0.

\section{RESULTS}

\section{Subjects}

The final sample comprised 148 subjects: mean \pm SD age $14.3 \pm 2.6$ years, height $164 \pm 13 \mathrm{~cm}$, and weight $59.3 \pm 15.5 \mathrm{~kg}$. Eighty-six (58\%) subjects presented as exertional dyspnea (DoE) with no underlying disorder, and 38 (26\%) had asthma. The remaining 24 (16\%) subjects ("other") comprised congenital heart disease $(n=7)$, pectus excavatum $(n=4)$, colitis $(n=2)$, bronchiectasis $(n=2)$, cardiac dysrhythmia $n=2$ ), plus one subject each with mediastinal fibrosis, postural tachycardia syndrome, CF-related metabolic syndrome, scoliosis with fused ribs, weakness, angioedema, and post-ARDS, presenting with dyspnea or chest pain on exertion. Lung function data are shown in Table 1.

\section{EFL During Exercise}

Expiratory flow limitation occurred at some point during exercise in 87 (59\%) subjects, over $49 \pm 21 \%$ (mean \pm SD) of tidal volume. Onset of EFL during exercise occurred in lighter exercise in those with more obstruction (greater concavity of resting maximum expiratory FVL) but not until peak exercise in those with normal spirometry (Pianosi, 2018b). Subjects with EFL achieved higher values for peak $\dot{\mathrm{VO}_{2}}$ with concomitant higher minute volume and $\mathrm{O}_{2}$ pulse at peak exercise (Table 2). No subjects exhibited $\mathrm{SpO}_{2}<94 \%$.

All subjects augmented tidal volume at onset of exercise by decreasing ERV. The effect of work level on ERV/VC did not show a linear trend as the largest change occurred between rest and light exercise, mirrored by a rise in IC/VC. Those who developed EFL maintained this strategy, causing IC/VC to rise further; whereas other subjects averted EFL by subsequently raising end-expiratory lung volume back to near resting levels, such that IC/VC remained relatively stable despite rising exercise intensity. Indeed, ERV/VC was consistently higher (all $p$-values < 0.002) and IC/VC consistently lower in (all $p$-values $<0.003$ ) non-EFL subjects once exercise began (Figure 1). The addition of an interaction term for $\mathrm{EFL}^{*}$ Work did not add significantly to the model fit $(p=0.27)$.

TABLE 1 | Pulmonary function test results, means (SD), split by EFL.

\begin{tabular}{|c|c|c|c|}
\hline & No EFL & EFL & $p$-value* \\
\hline FVC (\%pred) & 105 (15) & $101(17)$ & 0.16 \\
\hline FVC (L) & $3.94(1.05)$ & $3.85(1.20)$ & 0.65 \\
\hline $\mathrm{FEV}_{1}$ (\%pred) & $103(15)$ & $94(17)$ & 0.0007 \\
\hline $\mathrm{FEV}_{1}(\mathrm{~L})$ & 3.97 (1.06) & $3.32(0.59)$ & 0.09 \\
\hline $\mathrm{FEV}_{1} / \mathrm{FVC}$ & $0.86(0.07)$ & $0.88(0.08)$ & $<0.0001$ \\
\hline $\mathrm{FEF}_{50}$ (\%pred) & $81(23)$ & $64(22)$ & $<0.0001$ \\
\hline $\mathrm{FEF}_{50}\left(\mathrm{~L} \cdot \mathrm{S}^{-1}\right)$ & 4.09 (1.20) & $3.39(1.26)$ & 0.0008 \\
\hline $\mathrm{MW}\left(\mathrm{L} \cdot \mathrm{min}^{-1}\right)$ & 93 (28) & $98(37)$ & 0.37 \\
\hline
\end{tabular}

* Unpaired t-tests. 
TABLE 2 | Peak exercise results in each sex stratified by EFL.

\begin{tabular}{|c|c|c|c|c|}
\hline \multirow[b]{2}{*}{ Mean \pm SD } & \multicolumn{2}{|c|}{ Females } & \multicolumn{2}{|c|}{ Males } \\
\hline & No EFL $(N=43)$ & EFL $(N=46)$ & No EFL $(N=18)$ & EFL $(N=41)$ \\
\hline Age (years) & $14.9 \pm 2.0$ & $14.7 \pm 2.8$ & $13.6 \pm 3.5$ & $13.7 \pm 2.6$ \\
\hline Height (cm) & $163.4 \pm 7.6$ & $160.7 \pm 12.1$ & $165.7 \pm 20.2$ & $166.2 \pm 15.6$ \\
\hline Weight (kg) & $58.3 \pm 10.7$ & $57.0 \pm 13.4$ & $59.5 \pm 19.7$ & $62.8 \pm 19.9$ \\
\hline $\mathrm{BMI}\left(\mathrm{kg} \cdot \mathrm{m}^{2}\right)$ & $21.8 \pm 3.5$ & $21.8 \pm 4.0$ & $21.1 \pm 4.6$ & $22.3 \pm 4.6$ \\
\hline $\mathrm{BSA}\left(\mathrm{m}^{2}\right)$ & $1.62 \pm 0.16$ & $1.59 \pm 0.23$ & $1.65 \pm 0.37$ & $1.69 \pm 0.32$ \\
\hline Work (W) & $144 \pm 37$ & $160 \pm 56$ & $173 \pm 70$ & $185 \pm 69$ \\
\hline Work (\%pred*) & $88 \pm 23^{\dagger}$ & $102 \pm 24^{\dagger}$ & $77 \pm 19$ & $90 \pm 25$ \\
\hline$\dot{\mathrm{V}} \mathrm{O}_{2}\left(\mathrm{~mL} \cdot \mathrm{kg}^{-1} \cdot \mathrm{min}^{-1}\right)$ & $33.1 \pm 6.1^{\dagger}$ & $36.2 \pm 7.5^{\dagger}$ & $39.0 \pm 7.3$ & $39.5 \pm 9.2$ \\
\hline$\dot{\mathrm{V}} \mathrm{O}_{2}$ (\%predicted $\left.{ }^{*}\right)$ & $89.5 \pm 18.0$ & $99.1 \pm 19.4$ & $85.4 \pm 16.1$ & $88.3 \pm 17.5$ \\
\hline HR (beat.min ${ }^{-1}$ ) & $184 \pm 14$ & $185 \pm 11$ & $185 \pm 15$ & $185 \pm 13$ \\
\hline $\mathrm{O}_{2}$ pulse (mL.beat) & $10.4 \pm 2.3$ & $11.1 \pm 3.3$ & $12.3 \pm 41$ & $13.2 \pm 4.3$ \\
\hline $\mathrm{RR}$ (breath. $\mathrm{min}^{-1}$ ) & $47 \pm 9^{\ddagger}$ & $53 \pm 9^{\ddagger}$ & $55 \pm 16$ & $54 \pm 9$ \\
\hline VT (L) & $1.55 \pm 0.33$ & $1.58 \pm 0.52$ & $1.75 \pm 0.91$ & $1.77 \pm 0.66$ \\
\hline$\dot{V}_{E}\left(L \cdot \min ^{-1}\right)$ & $69.7 \pm 16.1 \square$ & $82.3 \pm 25.0^{\square}$ & $84.5 \pm 32.2$ & $93.1 \pm 34.6$ \\
\hline$\dot{V}_{E} / \dot{V} O_{2}$ & $37.6 \pm 5.9$ & $40.2 \pm 4.8$ & $37.3 \pm 5.8$ & $38.1 \pm 6.1$ \\
\hline RER & $1.15 \pm 0.08$ & $1.20 \pm 09$ & $1.16 \pm 0.12$ & $1.19 \pm 0.10$ \\
\hline $\mathrm{PetCO}_{2}(\mathrm{mmHg})$ & $35 \pm 4$ & $34 \pm 4$ & $35 \pm 4$ & $36 \pm 4$ \\
\hline
\end{tabular}

*Godfrey for Work Godfrey (1974) and Cooper et al. (1984). ${ }^{\dagger} p \leq 0.006,{ }^{\ddagger} p=0.001, \square p=0.01$ (t-test).

\section{Relationship to Symptoms}

Prevalence of EFL among the three groups is shown in Table 3. EFL was less common in subjects with DoE compared with the asthma or "other" groups ( $p=0.038)$. Dyspnea, alone or with leg fatigue, was cited by half the subjects as the reason for inability to continue at peak work, at similar rates in subjects with or without $\operatorname{EFL}(p=0.80)$.

\section{MVV vs. FVL}

Maximum voluntary ventilation was similar in EFL vs. nonEFL subjects, but only slightly better than chance at identifying subjects who developed EFL during exercise with an AUC of only 0.69 (95\% CI 0.61-0.78). AUC for multiples of $\mathrm{FEV}_{1}$ as surrogate measures for MVV are shown in Table 4. Having shown no difference in AUC among $\mathrm{FEV}_{1}$ multiples, Table 5 shows combinations of sensitivity and specificity for peak $\dot{V}_{E} / 30 \cdot \mathrm{FEV}_{1}$. The optimal cut-point from the AUC (Figure 2) was 0.853 (95\% CI $0.764-0.894)$, significantly better $(p<0.001)$ than MVV.

\section{DISCUSSION}

Measured MVV was only marginally better than chance at identifying subjects with ventilatory limitation whereas $\mathrm{FEV}_{1}$ was superior to 12 -s sprint MVV for estimation of maximum breathing capacity on exercise compared to EFL demonstrated by tidal FVL analysis. Use of MVV as the benchmark for maximal exercise is problematic in children. Healthy pre-pubertal children often achieve levels of peak $\dot{V}_{E}$ at or very close to MVV. Godfrey (Figure 4.2 of his book) speculated this observation was due to a mix of relatively high ventilatory requirements of younger children combined with their inability to properly perform an MVV maneuver (Godfrey, 1974). A recent study indeed found that $26 \%$ of children were unable to properly perform MVV maneuver (MacLean et al., 2016). ROC curve analysis confirmed that measured MVV is not particularly useful for concluding ventilatory limitation to exercise compared to FVL analysis. Ventilatory reserve is defined by peak exercise $\dot{V}_{E}$ as a fraction of MVV with the lower limit set at $15 \%$ (American Thoracic Society and American College of Chest Physicians, 2003). This cut-off is reasonable based on 95\% confidence limits of adult norms but is not independent of fitness or aging (Ross, 2003). Newer textbooks on pediatric exercise medicine state "one can infer that ventilatory reserve increases with age, at least for males" (Bar-Or and Rowland, 2004); and children achieve "near to or slightly less than $70 \%$ (of MVV) at maximal ventilation" (Fawkner, 2007). We submit that tidal FVL demonstrating EFL is the preferred method for this designation, but one can be confident without said analysis if the ratio of peak $\dot{V}_{E} / 30 \cdot \mathrm{FEV}_{1}$ exceeds 0.85 . Our data adds wanting scientific rigor and validity to current interpretation standards. This index provides a target peak $\dot{V}_{E}$ from which one can judge maximal effort; is similar to $\dot{V}_{E}$ sustainable by adolescents during eucapnic voluntary hyperpnea (Van der Eycken et al., 2016); and to a surrogate measure for MVV in exercising CF patients (Stein et al., 2003).

\section{EFL and Ventilatory Limitation vs. Exercise Limitation}

Numerous studies have been published using FVL analysis as a means of demonstrating ventilatory constraint to exercise despite limitations of the technique (Calverley and Koulouris, 2005). Exercise FVL have been used more often in adult studies but there is growing acceptance if not tacit recognition of its merits 


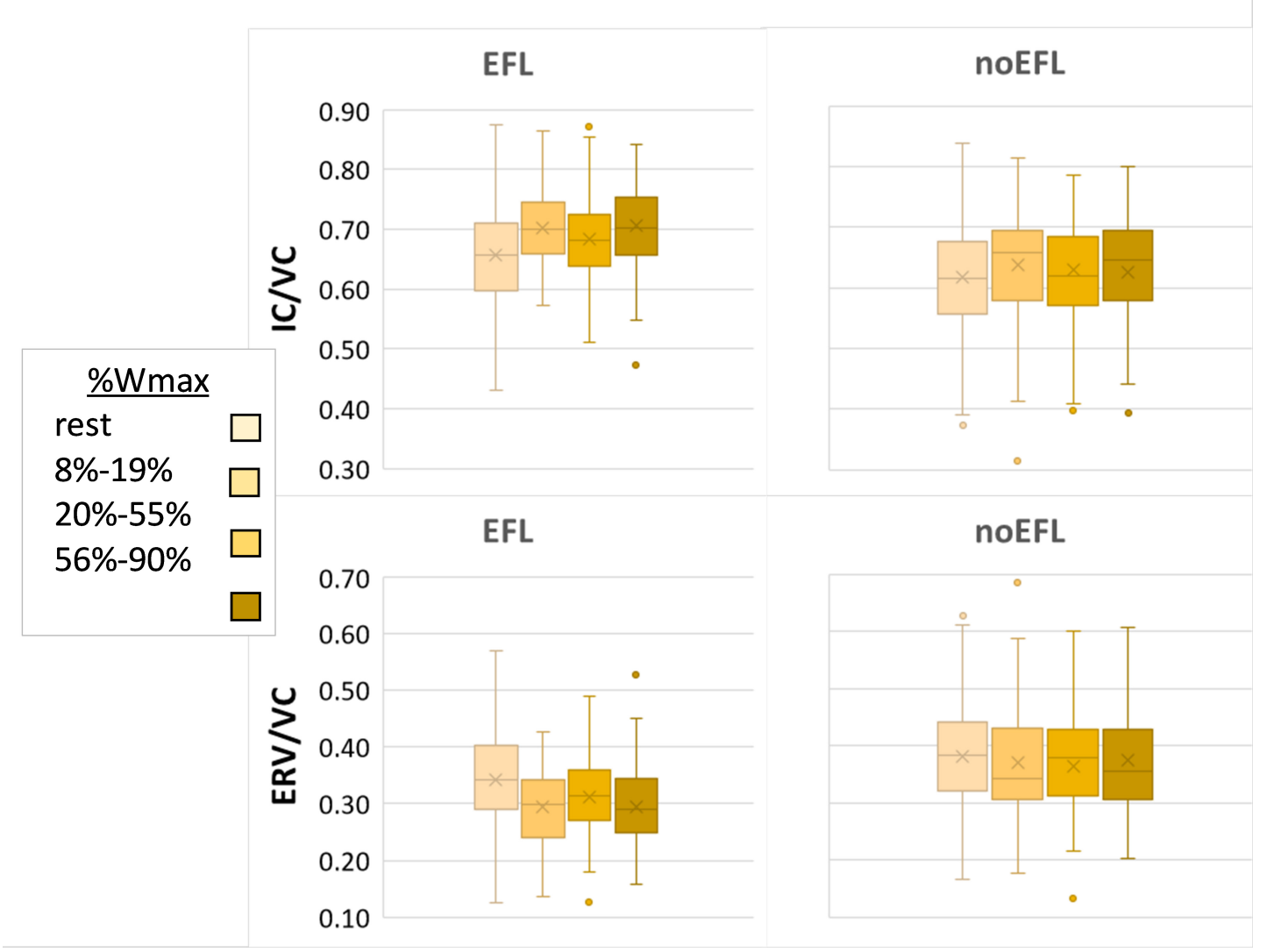

FIGURE 1 | Operating lung volume. Box and whisker plots of operating lung volume during exercise, expressed as ratio of inspiratory capacity (IC) or expiratory reserve volume (ERV) divided by vital capacity $(\mathrm{VC})$, in subjects according to presence or absence EFL in exercise. Box represents $25^{\text {th }}$ and $75^{\text {th }}$ centiles, with horizontal line representing median and $\mathrm{x}$ depicting mean value; dots are outliers.

and limitations to detect EFL during exercise. EFL is common in pre-pubertal children (Nourry et al., 2006; Swain et al., 2010), obese adolescents (Gibson et al., 2014), and more common in trained vs. untrained pediatric subjects (Nourry et al., 2005); but its prevalence falls after puberty from 90 to $45 \%$ in boys and from 90 to $20 \%$ in girls (Emerson et al., 2015; Smith et al., 2015) whose mean ages ranged from 14 to 15 years. Dysanaptic lung growth may contribute to this changing prevalence of EFL (Smith et al.,
2014). Nearly $60 \%$ of our subjects aged $14.3 \pm 2.6$ years had EFL during exercise indicating an enriched group with EFL among subjects evaluated for dyspnea. The incidence of EFL in males and females was $\sim 69$ and 52\%, respectively, which was higher than previously reported in the smaller cohort of post-pubescent adolescents (Emerson et al., 2015). This discrepancy is likely due to the inclusion of both pre, peri, and post- pubescent pediatric subjects in the present study; a caveat being gas compression

TABLE 3 | Stated cause for exercise cessation among the three diagnostic groups.

\begin{tabular}{|c|c|c|c|c|}
\hline EFL & No $(N=61)$ & Yes $(N=87)$ & Total $(N=148)$ & $p$-value \\
\hline \multicolumn{5}{|l|}{ Diagnostic group } \\
\hline DoE & $43(70 \%)$ & $43(49 \%)$ & $86(58 \%)$ & $0.038 *$ \\
\hline Asthma & $11(18 \%)$ & 27 (31\%) & 38 (26\%) & \\
\hline Other & $7(12 \%)$ & 17 (20\%) & 24 (16\%) & \\
\hline \multicolumn{5}{|l|}{ Reason to stop } \\
\hline Leg fatigue & 17 (28\%) & $20(23 \%)$ & 37 (25\%) & 0.6311 \\
\hline Dyspnea & 24 (39\%) & $30(35 \%)$ & 54 (36\%) & \\
\hline Fatigue & $11(18 \%)$ & 23 (26\%) & 34 (23\%) & \\
\hline Leg Fatigue +Dyspnea & $9(15 \%)$ & $14(16 \%)$ & $23(16 \%)$ & \\
\hline
\end{tabular}

*Pearson's $x^{2}$ test. 
TABLE 4 | Area under curve (AUC) results using MW and different multiples of $\mathrm{FEV}_{1}$ in denominator.

\begin{tabular}{|c|c|c|c|c|}
\hline Peak $\dot{V}_{E} / x \cdot \mathrm{FEV}_{1} x=$ & AUC (95\% Cl) & Best cutoff to maximize sensitivity and specificity & Sensitivity & Specificity \\
\hline 0.30 & $0.840^{*}(0.776,0.905)$ & 0.819 & 0.816 & 0.705 \\
\hline 0.35 & 0.840 & 0.702 & 0.816 & 0.705 \\
\hline 0.40 & 0.840 & 0.614 & 0.816 & 0.705 \\
\hline MW & $0.695(0.614,0.785)$ & 0.850 & 0.623 & 0.617 \\
\hline
\end{tabular}

*95\% Cl identical for different multiples of FEV 1 .

TABLE 5 | Exploration of cut-off values for peak $\dot{V}_{E} / 30 \mathrm{FEV}_{1}$ compared to current interpretation standard.

\begin{tabular}{lcccc}
\hline $\begin{array}{l}\text { Cut-point } \\
\text { peak } \dot{V}_{\boldsymbol{E}} / \mathbf{3 0} \cdot \mathbf{F E V} \mathbf{~}_{\mathbf{1}}\end{array}$ & Sensitivity (\%) & Specificity (\%) & PPV (\%) & NPV (\%) \\
\hline$>0.80$ & 86 & 61 & 72 & 79 \\
$>0.85$ & 76 & 78 & 80 & 74 \\
$>0.90$ & 63 & 86 & 84 & 67 \\
$\mathrm{MW}^{*}$ & 62 & 62 & 71 & 54 \\
\hline
\end{tabular}

PPV and NPV, positive and negative predictive values, respectively.

*Using value $>0.850$ for ratio of peak $\dot{\mathrm{V}}_{E} / M W$.

artifact that may overestimate EFL (see below). In addition, we found that females that exhibited EFL had greater peak $\dot{V} \mathrm{O}_{2}$, ventilation, and respiratory rate compared to females that did not exhibit EFL. These data suggest that girls who achieve higher workloads and metabolic rates are more likely to exhibit EFL during exercise similar to women (McClaran et al., 1998).

Mechanical constraints to $\dot{V}_{E}$ affect operating lung volume and breathing pattern during heavy exercise in subjects who experience EFL (McClaran et al., 1999). Babb postulated that onset of dynamic airway compression may be just as critical as EFL in evoking adjustments to minimize degree of EFL during exercise (Babb, 2013). Such strategic changes may demand more perfusion of the respiratory muscles potentially depriving working leg muscles (Harms et al., 1997), and leg muscle fatigue resulting from high-intensity exercise is at least partly due to increased inspiratory muscle work (Dempsey et al., 2006). Unloading the respiratory muscles by Heliox breathing resulted in small but statistically significant boost in performance at heavy exercise (Wilkie et al., 2015); whereas mechanical unloading with proportional-assist ventilation resulted in clinically significant improvement in performance at $90 \%$ peak $\dot{V} O_{2}$ (Harms et al., 2000). Hyperinflation attenuates stroke volume at rest and response to exercise in healthy controls (Stark-Leyva et al., 2004; Cheyne et al., 2018). There is likely a hierarchy of blood flow distribution during exercise between respiratory vs. locomotor musculatures and muscle afferent feedback influence fatigue and dyspnea (Sheel et al., 2018).

\section{Exertional Dyspnea}

Half the subjects cited breathing as the reason for exercise test cessation though no particular limiting symptom was cited more often among those with vs. without EFL. Some subjects continued to exercise despite developing EFL before finally stopping but one should not be surprised by an uncoupling ventilatory constraint and exercise limited by dyspnea. The most likely explanation is that some subjects raised end-expiratory lung volume during heavy exercise to counter impending or evolving EFL, which would have generated greater elastic work of breathing as lung compliance falls at higher lung volumes. One might then cease exercise due to dyspnea without EFL manifest. Subjects in this report chose their breathing strategy early during exercise, in virtually all subjects before EFL developed. Examination of Figure 2 suggests that subsequent behavior may perhaps have mitigated EFL but those with EFL clearly had lower endexpiratory lung volume than did those without EFL by heavy exercise. Results of studies in children offer disparate findings with respect to dyspnea in presence vs. absence of EFL (cf. Nourry et al., 2006; Swain et al., 2010) and studies in adults show similar discordance (Lovering et al., 2014; Wilkie et al., 2015). The reality is that our understanding of mechanisms of dyspnea in pediatrics is rudimentary (Pianosi, 2018a).

\section{Clinical Significance}

Triage of exertional dyspnea in pediatric populations is hindered by lack of data, forcing clinicians to rely on empiricism derived from adult subjects. Abu-Hasan and Weinberger concluded respiratory limitation from "restrictive" physiology as responsible if a subject's exercise ventilation fell within specified ranges of tidal volume, breath rate, and breathing reserve, based on extrapolation from adult studies (Abu-Hasan et al., 2005). Mahut et al. (2014) similarly concluded that the most frequent cause of exertional dyspnea in adolescents was "physiologic," defined as normal aerobic power and ventilatory response. The present study creates a novel paradigm for attribution of exertional dyspnea in pediatric subjects using data obtained from pediatric subjects and suggests a possible explanation. Just as Dominelli et al. (2015) stated some healthy individuals are more likely to exhibit mechanical constraints during exercise, one may postulate the respiratory system is culpable in pediatric subjects evaluated for exertional dyspnea, particularly females who push themselves (Table 2). We believe it is no coincidence that exercise enhances every component of the $\mathrm{O}_{2}$ transport system except the lungs. Ergo, the lungs may contribute to the limitation of peak $\dot{V} O_{2}$ (Wagner, 2005).

\section{Limitations}

There are caveats when using exercise tidal FVL to determine EFL (Guenette et al., 2010, 2013; Dominelli and Sheel, 2012). First, among alternative methods, only negative expiratory pressure (NEP) technique has been employed in pediatrics and only in infants (Jones et al., 2000). We did not measure 


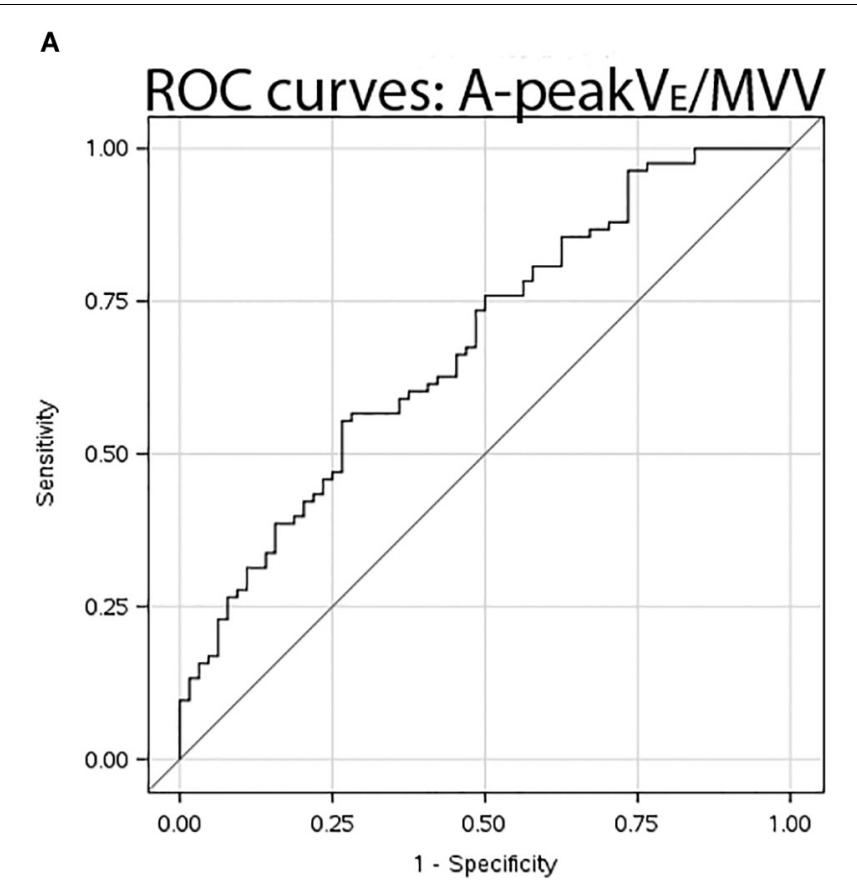

B

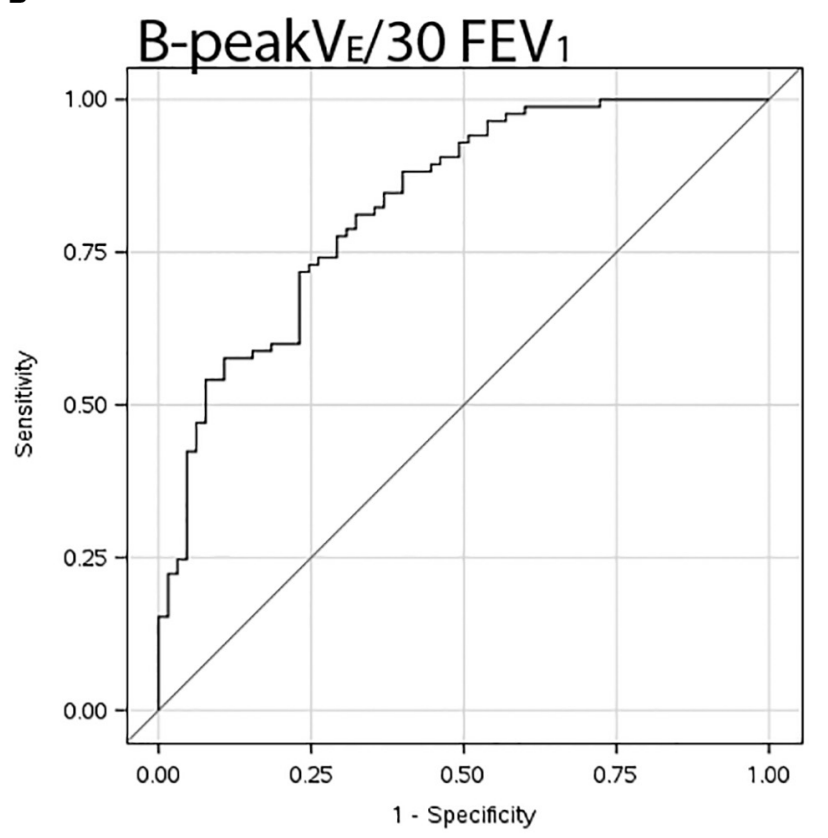

FIGURE 2 | ROC curves. Receiver operating characteristic curves illustrating sensitivity and specificity of (A) 12-s sprint MVV in denominator for peak $\dot{V}_{E} / M V V$, and (B) proxy measure for MVV viz. peak $\dot{V}_{E} / 30 \cdot F E V_{1}$.

IC at peak exercise, meaning placement of tidal breaths at peak exercise was based on IC maneuvers done at work up to $90 \%$ peak work. However, Nourry et al. (2006) showed minimal change in end-expiratory lung volume from this range to peak work. Second, the best acceptable maximum flow-volume curve at rest (pre-exercise) was used to place the exercise FVL within its maximum envelope. Swain et al. (2010) noted only $\sim 3 \%$ difference between pre- and posttest maximum expiratory flow-volume curves. We essentially doubled this inherent variability when choosing our EFL threshold. Moreover, said factors could affect determination of EFL in either direction, and any bias should be nullified given the sample size, as these pitfalls could positively or negatively influence EFL adjudication. The effect of thoracic gas compression on FVLs when volume is measured at the mouth may affect identification of EFL during exercise, but there are no data concerning this in children and adolescents; and any presumption that adult studies apply to children or adolescents should be viewed with skepticism in view of the high prevalence of EFL in children. Though certainly present, we truly do not know the volume gas compression in pediatric subjects during exercise. During routine spirometry, its magnitude is unpredictable (Coates et al., 1988) but, with few exceptions, one would expect it to be small in the population reported herein, most of whom had normal spirometry. Our subject sample did not include patients with cystic fibrosis. Indeed, Stein et al. (2003) proposed an equation for calculating MVV based on $\mathrm{FEV}_{1}$ in CF patients which performed nearly as well as an $\mathrm{FEV}_{1}$-based proxy measure, and which is very similar to our selection of $30 \cdot \mathrm{FEV}_{1}$. Finally, dyspnea ratings were not recorded because existing dyspnea scales had dubious validity in children when testing began in 2007. We recently published our validation studies in pediatric subjects (Pianosi et al., 2014, 2015), and found remarkable similarity in dyspnea ratings during exercise among healthy controls, subjects with asthma, or cystic fibrosis.

\section{CONCLUSION}

30. $\mathrm{FEV}_{1}$ is superior to MVV for assessing potential ventilatory limitation to exercise defined as $>5 \%$ overlap of exercise (tidal FVL with maximal expiratory FVL) in pediatric subjects if tidal FVL analysis is unavailable and could be used to decide whether a child or adolescent experiences exercise limitation due to the respiratory pump. ROC analysis for breathing reserve $<0.15$ yields positive predictive value of nearly $80 \%$ and negative predictive value of $75 \%$ for detecting EFL.

\section{Future Directions}

Defining EFL is still a moving target which will be subject to change as our understanding of, and limitations to, using tidal FVL analysis to determine ventilatory limitation. There are caveats when using exercise tidal FVL to determine EFL, chief among which are understanding how thoracic gas compression during a forced expiratory maneuver or during active exhalation such as may occur during heavy exercise may affect flow rate at any given lung volume, so more research is necessary in this domain. Ideally, this should be explored by plotting isovolume pressure-flow diagrams, or employing NEP technique 
(Eltayara et al., 1996), to quantify how thoracic gas compression affects FVL during exercise in pediatric subjects.

\section{ETHICS STATEMENT}

The study meets the guidelines for ethical conduct and report of research, and was approved the Mayo Clinic IRB study ID\# 14-009335.

\section{AUTHOR CONTRIBUTIONS}

PP supervised exercise testing, collated and data, and wrote initial draft. JS revised the manuscript.

\section{REFERENCES}

Abu-Hasan, M., Tannous, B., and Weinberger, M. (2005). Exercise-induced dyspnea in children and adolescents: if not asthma then what? Ann. Allergy Asthma Immunol. 94, 366-371. doi: 10.1016/S1081-1206(10)60989-1

Agostoni, P., Apostolo, A., and Sciomer, S. (2011). Evolution of the concept of ventilatory limitation during exercise. Combining the pneumologist and cardiologist point of view. Respir. Physiol. Neurobiol. 179, 127-128. doi: 10.1016/j.resp.2011.09.002

American Thoracic Society and American College of Chest Physicians (2003). ATS/ACCP statement on cardiopulmonary exercise testing. Am. J. Respir. Crit. Care Med. 167, 211-277. doi: 10.1164/rccm.167.2.211

Armstrong, N., Kirby, B. J., McManus, A. M., and Welsman, J. R. (1997). Prepubescents' ventilatory responses to exercise with reference to sex and body size. Chest 112, 1554-1560. doi: 10.1378/chest.112.6.1554

Babb, T. G. (2013). Exercise ventilatory limitation: the role of expiratory flow limitation. Exerc. Sport Sci. Rev. 41, 11-18. doi: 10.1097/JES.0b013e318267c0d2

Bar-Or, O., and Rowland, T. W. (eds). (2004). "Physiologic and perceptual responses to exercise in healthy children," in Pediatric Exercise Medicine, (Champaign, IL: Human Kinetics).

Borel, B., Leclair, E., Thevenet, D., Beghin, L., Gottrand, F., and Fabre, C. (2014). Mechanical ventilatory constraints during incremental exercise in healthy and cystic fibrosis children. Pediatr. Pulmonol. 49, 221-229. doi: 10.1002/ppul. 22804

Calverley, P. M., and Koulouris, N. G. (2005). Flow limitation and dynamic hyperinflation: key concepts in modern respiratory physiology. Eur. Respir. J. 25, 186-199. doi: 10.1183/09031936.04.00113204

Cheyne, W. S., Gelinas, J. C., and Eves, N. D. (2018). Hemodynamic effects of incremental lung hyperinflation. Am. J. Physiol. Heart Circ. Physiol. 315, H474-H481. doi: 10.1152/ajpheart.00229.2018

Coates, A. L., Desmond, K. J., Demizio, D., Allen, P., and Beaudry, P. H. (1988). Sources of error in flow-volume curves. Effect of expired volume measured at the mouth vs that measured in a body plethysmograph. Chest 94, 976-982. doi: 10.1378/chest.94.5.976

Colwell, K. L., and Bhatia, R. (2017). Calculated versus measured MVVsurrogate marker of ventilatory CPET. Med. Sci. Sports Exerc. 49, 1987-1992. doi: 10.1249/MSS.0000000000001318

Cooper, D. M., Kaplan, M. R., Baumgarten, L., Weiler-Ravell, D., Whipp, B. J., and Wasserman, K. (1987). Coupling of ventilation and $\mathrm{CO}_{2}$ production during exercise in children. Pediatr. Res. 21, 568-572. doi: 10.1203/00006450198706000-00012

Cooper, D. M., Weiler-Ravell, D., Whipp, B. J., and Wasserman, K. (1984). Aerobic parameters of exercise as a function of body size during growth in children. $J$. Appl. Physiol. 56, 628-634. doi: 10.1152/jappl.1984.56.3.628

Dempsey, J. A., McKenzie, D. C., Haverkamp, H. C., and Eldridge, M. W. (2008). Update in the understanding of respiratory limitations to exercise performance in fit, active adults. Chest 134, 613-622. doi: 10.1378/chest. 07-2730

\section{FUNDING}

This work was financially supported by the Mayo Clinic CTSA through grant number UL1 TR000135 from the National Center for Advancing Translational Sciences, a component of the National Institutes of Health, via Small Grant Award from Department of Pediatric and Adolescent Medicine.

\section{ACKNOWLEDGMENTS}

The authors thank Katherine King and Christine Lohse of Mayo Clinic and Fiona Reid of King's College, London, for statistical support and Alicia Woodward for assistance in data extraction.

Dempsey, J. A., Romer, L., Rodman, J., Miller, J., and Smith, C. (2006). Consequences of exercise-induced respiratory muscle work. Respir. Physiol. Neurobiol. 151, 242-250. doi: 10.1016/j.resp.2005.12.015

Dominelli, P. B., Molgat-Seon, Y., Bingham, D., Swartz, P. M., Road, J. D., Foster, G. E., et al. (2015). Dysanapsis and the resistive work of breathing during exercise in healthy men and women. J. Appl. Physiol. 119, 1105-1113. doi: 10.1152/japplphysiol.00409.2015

Dominelli, P. B., and Sheel, A. W. (2012). Experimental approaches to the study of the mechanics of breathing during exercise. Respir. Physiol. Neurobiol. 180, 147-161. doi: 10.1016/j.resp.2011.10.005

Eltayara, L., Becklake, M. R., Volta, C. A., and Milic-Emili, J. (1996). Relationship between chronic dyspnea and expiratory flow limitation in patients with chronic obstructive pulmonary disease. Am. J. Respir. Crit. Care Med. 154(6 Pt 1), 1726-1734. doi: 10.1164/ajrccm.154.6.8970362

Emerson, S. R., Kurti, S. P., Rosenkranz, S. K., Smith, J. R., and Harms, C. A. (2015). Decreased prevalence of exercise expiratory flow limitation from preto postpuberty. Med. Sci. Sports Exerc. 47, 1503-1511. doi: 10.1249/MSS. 0000000000000566

Fawkner, S. G. (2007). "Pulmonary function," in Pediatric Exercise Physiology, ed. N. Armstrong (Toronto: Churchill Livingstone Elsevier), 127-133. doi: 10.1016/ B978-0-443-10260-8.50011-4

Fulton, J. E., Pivarnik, J. M., Taylor, W. C., Snider, S. A., Tate, A. L., and Frankowski, R. F. (1995). Prediction of maximum voluntary ventilation (MVV) in AfricanAmerican adolescent girls. Pediatr. Pulmonol. 20, 225-233. doi: 10.1002/ppul. 1950200405

Giardini, A., Odendaal, D., Khambadkone, S., and Derrick, G. (2011). Physiologic decrease of ventilatory response to exercise in the second decade of life in healthy children. Am. Heart J. 161, 1214-1219. doi: 10.1016/j.ahj.2011.03.008

Gibson, N., Johnston, K., Bear, N., Stick, S., Logie, K., and Hall, G. L. (2014). Expiratory flow limitation and breathing strategies in overweight adolescents during submaximal exercise. Int. J. Obes. 38, 22-26. doi: 10.1038/ijo.2013.137

Godfrey, S. (1974). Exercise Testing in Children. London: WB Saunders.

Guenette, J. A., Chin, R. C., Cory, J. M., Webb, K. A., and O’Donnell, D. E. (2013). Inspiratory capacity during exercise: measurement, analysis, and interpretation. Pulm. Med. 2013:956081. doi: 10.1155/2013/956081

Guenette, J. A., Dominelli, P. B., Reeve, S. S., Durkin, C. M., Eves, N. D., and Sheel, A. W. (2010). Effect of thoracic gas compression and bronchodilation on the assessment of expiratory flow limitation during exercise in healthy humans. Respir. Physiol. Neurobiol. 170, 279-286. doi: 10.1016/j.resp.2010.01.017

Harms, C. A., Babcock, M. A., McClaran, S. R., Pegelow, D. F., Nickele, G. A., Nelson, W. B., et al. (1997). Respiratory muscle work compromises leg blood flow during maximal exercise. J. Appl. Physiol. 82, 1573-1583. doi: 10.1152/ jappl.1997.82.5.1573

Harms, C. A., Wetter, T. J., St Croix, C. M., Pegelow, D. F., and Dempsey, J. A. (2000). Effects of respiratory muscle work on exercise performance. J. Appl. Physiol. 89, 131-138. doi: 10.1152/jappl.2000.89.1.131

James, F. W. (1981). Exercise testing in normal individuals and patients with cardiovascular disease. Cardiovasc. Clin. 11, 227-246. 
Johnson, B. D., Scanlon, P. D., and Beck, K. C. (1995). Regulation of ventilatory capacity during exercise in asthmatics. J. Appl. Physiol. 79, 892-901. doi: 10.1152/jappl.1995.79.3.892

Jones, M. H., Davis, S. D., Kisling, J. A., Howard, J. M., Castile, R., and Tepper, R. S. (2000). Flow limitation in infants assessed by negative expiratory pressure. Am. J. Respir. Crit. Care Med. 161(3 Pt 1), 713-717. doi: 10.1164/ajrccm.161.3. 9807135

Klas, J. V., and Dempsey, J. A. (1989). Voluntary versus reflex regulation of maximal exercise flow: volume loops. Am. Rev. Respir. Dis. 139, 150-156. doi: 10.1164/ajrccm/139.1.150

Knudson, R. J., Lebowitz, M. D., Holberg, C. J., and Burrows, B. (1983). Changes in the normal maximal expiratory flow-volume curve with growth and aging. Am. Rev. Respir. Dis. 127, 725-734. doi: 10.1164/arrd.1983.127 .6 .725

Lovering, A. T., Elliott, J. E., Laurie, S. S., Beasley, K. M., Gust, C. E., Mangum, T. S., et al. (2014). Ventilatory and sensory responses in adult survivors of preterm birth and bronchopulmonary dysplasia with reduced exercise capacity. Ann. Am. Thorac. Soc. 11, 1528-1537. doi: 10.1513/AnnalsATS.201312-466OC

MacLean, J. E., DeHaan, K., Fuhr, D., Hariharan, S., Kamstra, B., Hendson, L., et al. (2016). Altered breathing mechanics and ventilatory response during exercise in children born extremely preterm. Thorax 71, 1012-1019. doi: 10.1136/thoraxjnl-2015-207736

Mahut, B., Fuchs-Climent, D., Plantier, L., Karila, C., Refabert, L., ChevalierBidaud, B., et al. (2014). Cross-sectional assessment of exertional dyspnea in otherwise healthy children. Pediatr. Pulmonol. 49, 772-781. doi: 10.1002/ppul. 22905

McClaran, S. R., Harms, C. A., Pegelow, D. F., and Dempsey, J. A. (1998). Smaller lungs in women affect exercise hyperpnea. J. Appl. Physiol. 84, 1872-1881. doi: 10.1152/jappl.1998.84.6.1872

McClaran, S. R., Wetter, T. J., Pegelow, D. F., and Dempsey, J. A. (1999). Role of expiratory flow limitation in determining lung volumes and ventilation during exercise. J. Appl. Physiol. 86, 1357-1366. doi: 10.1152/jappl.1999.86.4.1357

Miller, M. R., Crapo, R., Hankinson, J., Brusasco, V., Burgos, F., Casaburi, R., et al. (2005). General considerations for lung function testing. Eur. Respir. J. 26, 153-161. doi: 10.1183/09031936.05.00034505

Nourry, C., Deruelle, F., Fabre, C., Baquet, G., Bart, F., Grosbois, J. M., et al. (2005). Exercise flow-volume loops in prepubescent aerobically trained children. J. Appl. Physiol. 99, 1912-1921. doi: 10.1152/japplphysiol.00323.2005

Orenstein, D. M. (1993). "Assessment of exercise pulmonary function," in Pediatric Laboratory Exercise Testing: Clinical Guidelines, ed. T. W. Rowland (Champaign, IL: Human Kinetics), 141.

Nourry, C., Deruelle, F., Fabre, C., Baquet, G., Bart, F., Grosbois, J. M., et al. (2006). Evidence of ventilatory constraints in healthy exercising prepubescent children. Pediatr. Pulmonol. 41, 133-140. doi: 10.1002/ppul.20332

Pianosi, P. T. (2018a). Exertional dyspnea in childhood: is there an iceberg beneath the apex? Pediatr. Exerc. Sci. 30, 442-449. doi: 10.1123/pes.2018-0167

Pianosi, P. T. (2018b). Flow limitation and dysanapsis in children and adolescents with exertional dyspnea. Respir. Physiol. Neurobiol. 252-253, 58-63. doi: 10.1016/j.resp.2018.03.013

Pianosi, P. T., Huebner, M., Zhang, Z., and McGrath, P. J. (2014). Dalhousie Dyspnea and perceived exertion scales: psychophysical properties in children and adolescents. Respir. Physiol. Neurobiol. 199, 34-40. doi: 10.1016/j.resp.2014. 04.003

Pianosi, P. T., Huebner, M., Zhang, Z., Turchetta, A., and McGrath, P. J. (2015). Dalhousie pictorial scales measuring dyspnea and perceived exertion during exercise for children and adolescents. Ann. Am. Thorac. Soc. 12, 718-726. doi: 10.1513/AnnalsATS.201410-477OC

Prioux, J., Ramonatxo, M., Mercier, J., Granier, P., Mercier, B., and Prefaut, C. (1997). Changes in maximal exercise ventilation and breathing pattern in boys during growth: a mixed cross-sectional longitudinal study. Acta Physiol. Scand. 161, 447-458. doi: 10.1046/j.1365-201X.1997.00245.x

Ross, R. M. (2003). ATS/ACCP statement on cardiopulmonary exercise testing. Am. J. Respir. Crit. Care Med. 167:1451. doi: 10.1164/ajrccm.167.10.950

Rowland, T. W., and Cunningham, L. N. (1997). Development of ventilatory responses to exercise in normal white children. A longitudinal study. Chest 111, 327-332. doi: 10.1378/chest.111.2.327

Sheel, A. W., Boushel, R. C., and Dempsey, J. A. (2018). Competition for blood flow distribution between respiratory and locomotor muscles: implications for muscle fatigue. J. Appl. Physiol. 125, 820-831. doi: 10.1152/japplphysiol.00189. 2018

Smith, J. R., Emerson, S. R., Kurti, S. P., Gandhi, K., and Harms, C. A. (2015). Lung volume and expiratory flow rates from pre- to post-puberty. Eur. J. Appl. Physiol. 115, 1645-1652. doi: 10.1007/s00421-015-3149-1

Smith, J. R., Rosenkranz, S. K., and Harms, C. A. (2014). Dysanapsis ratio as a predictor for expiratory flow limitation. Respir. Physiol. Neurobiol. 198, 25-31. doi: 10.1016/j.resp.2014.04.001

Stark-Leyva, K. N., Beck, K. C., and Johnson, B. D. (2004). Influence of expiratory loading and hyperinflation on cardiac output during exercise. J. Appl. Physiol. 96, 1920-1927. doi: 10.1152/japplphysiol.00756.2003

Stein, R., Selvadurai, H., Coates, A., Wilkes, D. L., Schneiderman-Walker, J., and Corey, M. (2003). Determination of maximal voluntary ventilation in children with cystic fibrosis. Pediatr. Pulmonol. 35, 467-471. doi: 10.1002/ppul.10298

Swain, K. E., Rosenkranz, S. K., Beckman, B., and Harms, C. A. (2010). Expiratory flow limitation during exercise in prepubescent boys and girls: prevalence and implications. J. Appl. Physiol. 108, 1267-1274. doi: 10.1152/japplphysiol.00123. 2009

Takken, T., Bongers, B. C., van Brussel, M., Haapala, E. A., and Hulzebos, E. H. J. (2017). Cardiopulmonary exercise testing in pediatrics. Ann. Am. Thorac. Soc. 14(Suppl._1), S123-S128. doi: 10.1513/AnnalsATS.201611-912FR

Van der Eycken, S., Schelpe, A., Marijsse, G., Dilissen, E., Troosters, T., Vanbelle, V., et al. (2016). Feasibility to apply eucapnic voluntary hyperventilation in young elite athletes. Respir. Med. 111, 91-93. doi: 10.1016/j.rmed.2015. 12.012

Wagner, P. D. (2005). Why doesn't exercise grow the lungs when other factors do? Exerc. Sport Sci. Rev. 33, 3-8.

Wilkie, S. S., Dominelli, P. B., Sporer, B. C., Koehle, M. S., and Sheel, A. W. (2015). Heliox breathing equally influences respiratory mechanics and cycling performance in trained males and females. J. Appl. Physiol. 118, 255-264. doi: 10.1152/japplphysiol.00400.2014

Conflict of Interest Statement: The authors declare that the research was conducted in the absence of any commercial or financial relationships that could be construed as a potential conflict of interest.

Copyright (c) 2019 Pianosi and Smith. This is an open-access article distributed under the terms of the Creative Commons Attribution License (CC BY). The use, distribution or reproduction in other forums is permitted, provided the original author(s) and the copyright owner(s) are credited and that the original publication in this journal is cited, in accordance with accepted academic practice. No use, distribution or reproduction is permitted which does not comply with these terms. 